\title{
Delayed action and uncertain stabilisation targets. How much will the delay cost?
}

\author{
Valentina Bosetti • Carlo Carraro • \\ Alessandra Sgobbi • Massimo Tavoni
}

Received: 2 June 2008 / Accepted: 6 March 2009 / Published online: 23 July 2009

(C) Springer Science + Business Media B.V. 2009

\begin{abstract}
Despite the growing concern about actual on-going climate change, there is little consensus on the scale and timing of actions needed to stabilise the concentrations of greenhouse gases. Many countries are unwilling to implement mitigation strategies, at least in the short term, and no agreement on an ambitious global stabilisation target has yet been reached. It is thus likely that international climate policies will be characterized by a high degree of uncertainty over the stringency of the climate objective, and that some countries might delay their participation to global action. What additional economic costs will this delay in the adoption of
\end{abstract}

This paper is part of the research work being carried out by the Climate Change Modelling and Policy Research Programme of the Fondazione Eni Enrico Mattei and by the Climate Impacts and Policy Division of the EuroMediterranean Center on Climate Change. Financial support from the Italian Ministry of the Environment is acknowledged. The financial support of the EC 6FP TranSust.Scan project-Scanning Policy Scenarios for the Transition to Sustainable Economic Structures-is gratefully acknowledged. The authors are grateful for useful comments from participants to the Conference on the "Economics of Climate Change and Sustainable Development", Chia, Italy, September 2007. The usual disclaimer applies.

V. Bosetti · C. Carraro · A. Sgobbi · M. Tavoni $(\varangle)$

Fondazione Eni Enrico Mattei, Corso Magenta 63, Milan, Italy

e-mail: massimo.tavoni@feem.it

V. Bosetti - C. Carraro - A. Sgobbi - M. Tavoni

CMCC, Lecce, Italy

C. Carraro

University of Venice, Venice, Italy

C. Carraro

CEPR, London, UK

C. Carraro

CESifo, Munich, Germany

M. Tavoni

Catholic University of Milan, Milan, Italy 
mitigation measures imply? What would the optimal short-term strategy be given the uncertainty surrounding the climate policy to come? Is there a hedging strategy that decision makers can adopt to cope with delayed action and uncertain targets? This paper addresses these questions by quantifying the economic implications of delaying mitigation action, and by computing the optimal abatement strategy in the presence of uncertainty about a global stabilisation target (which will be agreed upon in future climate negotiations). Results point to short-term inaction as the key determinant for the economic costs of ambitious climate policies. They also indicate that there is an effective hedging strategy that could minimise the cost of climate policy uncertainty over the global stabilisation target: a short-term moderate climate policy would be a good strategy to reduce the costs of delayed action and to cope with uncertainty about the outcome of future climate negotiations. By contrast, failing to curb emissions in the short term imposes rapidly increasing additional costs of compliance.

\section{Introduction}

According to the latest IPCC report (IPCC 2007), there is unequivocal evidence that the climate system is warming, and this is affecting both average air and ocean temperatures, thus causing widespread snow and ice melts and the rise of average sea levels. Global warming is also expected to affect both ecosystems and socioeconomic systems to varying degrees, even though the impacts on natural and human environments are partly offset by autonomous adaptation actions and nonclimate related drivers. The IPCC also points to widespread agreement over the fact that such changes in the climate system may be fuelled by global greenhouse gas emissions from human activities, which increased by $70 \%$ between 1970 and 2004 . If emissions continue unabated, the average global surface temperature is likely to rise by an additional $1.8-4.0^{\circ} \mathrm{C}$ this century (IPCC 2007). A $2^{\circ} \mathrm{C}$ temperature increase is suggested to be a threshold beyond which irreversible and possibly catastrophic changes in natural ecosystems - and hence in socio-economic systems - might occur.

Parallel to this growing consensus on the scientific bases for climate change, the climate challenge has become a public policy priority, and is now ranking high in some, if not all, countries' political agendas. While policymakers recognise that climate change is a threat that requires widespread cooperation on an unprecedented level, they face great uncertainties, both in relation to the magnitude and severity of the impacts of climate change, and the costs of alternative mitigation strategies. The long-term stabilisation target remains an essentially political decision, and there is little agreement over what the ultimate target should be. Policymakers therefore face an additional uncertainty: while they do expect some form of global action to be required, they do not know which countries are going to sign a climate agreement, nor do they know the ultimate climate stabilisation target that such an agreement will set.

The UNFCCC has put forward a qualitative long-term climate stabilisation target, ${ }^{1}$ but we are still far from reaching an agreement about the quantitative

\footnotetext{
${ }^{1}$ The target is to reach atmospheric stabilisation at concentration levels that would prevent dangerous anthropogenic interference with the global climate.
} 
interpretation of this target. The Kyoto Protocol of the UN Framework Convention on Climate Change in itself contains important policy decisions, such as the introduction of emission trading and Clean Development Mechanisms (CDM), but it falls short of a definite and effective response to climate change at a global level. Moreover, the first commitment period of the Protocol ends in 2012, and there is still great uncertainty over the details of any new global climate deal. Negotiations are already underway to define a post-Kyoto framework, and several proposals have appeared in both academic and policy literature (see, for instance, IEA 2002; Aldy and Stavins 2007; Stern 2008). However, little consensus on a given framework has emerged so far.

Two broad political positions over the ultimate climate stabilisation target can be identified. On the one hand, the European Union is taking the lead, demanding bold actions from its member states to meet the reduced emission targets agreed upon in the Kyoto protocol ${ }^{2}$ and beyond 2012 (expiry of the Kyoto target). The EU and its member states are calling for concerted action to contain the global temperature increase over this century within the $2^{\circ} \mathrm{C}$ threshold. ${ }^{3}$ On the other hand, less proactive countries - notably the US - tend to focus on a less stringent stabilisation target (around 650 ppmv for all greenhouse gases, see for example, Newell and Hall 2007), which is expected to keep temperature increase at or below $3^{\circ} \mathrm{C}$ by the end of the century.

The first contribution of our analysis is a plain assessment of the possible consequences of a "no climate action" strategy should one of these two alternative policies be agreed upon with a 20 years delay. This assessment allows us to quantify the costs of inaction towards the achievement of climate protection goals, providing useful short-term policy insights, and sets the stage for the more refined evaluation of uncertainty that constitutes the central core of the paper.

Indeed, most of the literature (see Ingham et al. 2007 for a review) has so far examined whether the expectation of gaining better information on the severity of climate change impacts and the costs of mitigation actions should induce policymakers to wait before acting, or whether the possibility of worse than expected climate change impacts should lead policymakers to take more stringent immediate action to avoid a necessity for abrupt and costly policy changes in the future. Even though results are not unequivocal, they seem to indicate that in general, the prospect of learning new information would lead to a reduction in current abatement efforts. One of the main reasons which supporters of the learn-then-act argument put forward is that we still lack sufficient knowledge to define which level of emissions could prevent dangerous climate change and, since this uncertainty may be resolved through research and learning, we should delay expensive mitigation actions until we have a better understanding. The argument is that if we take stringent mitigation actions now, and then find out that the impacts of climate change are less significant than expected, we would have incurred unnecessary costs. On the other hand, if we learn that climate change impacts are more severe, we can start undertaking stringent measures and accelerate action. So, for instance, in a much cited paper, Wigley et al. (1996) explore the appropriate timing of $\mathrm{CO}_{2}$ abatement actions and conclude that,

\footnotetext{
${ }^{2}$ Emissions in 2008-2012 should be 8\% below 1990 levels.

${ }^{3}$ EC Communication (2007) "Limiting Global Climate Change to 2 degrees Celsius: The way ahead for 2020 and beyond".
} 
in general, the overall costs of reducing emissions are lower if the majority of the effort is deferred to the future. Similar results are found by Richels and Edmonds (1997) and Kosobud et al. (1994) among others.

Manne and Richels (1995) use an integrated assessment model to explore the implications of uncertainty on the severity of climate change impacts. They find that if there is a prospect of resolving such uncertainty, the optimal path of emissions reduction varies considerably with respect to the optimal path without uncertainty. In particular, the earlier the uncertainty is resolved, the more it pays to wait before taking action. Similar results are found by Nordhaus and Popp (1997). Strengthening these results, Ulph and Ulph (1997) find that even when the climate system risks undergoing irreversible shifts, uncertainty does not lead to higher abatement efforts. Even by introducing learning from previous observation (though imperfect), as in Karp and Zhang (2006), abatement efforts decrease relative to the case in which no learning is possible - and the decrease is more marked when uncertainty is large, that is, when the potential scope to benefit from learning is greater.

On the other hand, advocates for immediate action invoke the precautionary principle, particularly given the risk of triggering irreversible changes in the climate system. The slow process of greenhouse gas accumulation and atmospheric decay (see Fisher 2002) may indeed imply that, if we fail to take action to reduce emissions now and find out at a later date that climate change is more serious than expected, we may no longer be able to reverse the climatic changes that have been triggered, no matter how stringent a policy we implement. For instance, Schneider and Goulder (1997) argue that, even though there are compelling arguments for implementing relatively mild mitigation measures in the short term, this should not justify the absence of policy action now, because it could lower abatement costs in the future.

A different strand of research has emerged more recently, which explicitly recognises that the choice of a global stabilisation target is ultimately a political decision, and explores the impact of such uncertainty on policy makers' choices. So, for instance, Ha-Duong and co-authors (Ha-Duong et al. 1997) use a stylised model to determine the optimal mitigation choices given uncertainty about the stabilisation target. They find that the existing inertia in investment decisions increases the costs of delayed actions, and that, in the presence of uncertainty about future climate targets, it is cost-effective to spread mitigation actions across generations. Similarly, Yohe et al. (2004) explore a different kind of climate uncertainty, notably uncertainty over the target that policymakers may wish-or have to-achieve in the future. The authors find that imposing a carbon tax other than zero is a better strategy than doing nothing until full information becomes available. The results of these last two papers support a policy strategy which starts at moderate levels but increases its stringency if future information on impacts of climate change confirms their relevance. Finally, in Bahn et al. (2008) uncertainty on future climate policies is dealt with by implementing stochastic control methods. Their conclusions, based on a simplified model with a more refined representation of uncertainty, are consistent with those presented in this paper.

The analysis carried out in this paper contributes to the literature by means of a numerical evaluation of the interplay of uncertainty over a future climate commitment, and the emission mitigation and energy investment strategies that are optimal in the short term. The investigation is taken several steps forward. First, we apply state-of-the-art stochastic programming techniques to retrieve the optimal 
strategy endogenously, that is within a single optimisation. Second, we carry out the analysis using an integrated assessment model that features a realistic description of the mitigation options in the energy sector as well as induced technological change. This allows us to go beyond stylised modelling representations and to evaluate the impact of uncertainty over the ultimate climate stabilisation target on the optimal portfolio of abatement technologies and innovation. The indications resulting from the methodology we employ suggest that an early emission reduction policy is the best hedging strategy we are left with, and that the penalty of failing to endorse such a policy is significantly higher if we under-mitigate.

The paper is organised as follows. We begin by exploring the economic implications of delaying mitigation actions (Section 2). We are thus able to quantify how climate policy costs depend upon inaction time, providing useful information for future international climate agreements. Then, we analyse how uncertainty surrounding the stringency of future climate targets affects early abatement, technology choices and innovation strategies (Section 3). By explicitly incorporating uncertainty into decision making, we provide a risk management approach that can help policymakers in the choice of optimal hedging strategies. The paper is concluded with a summary of the main results and a discussion of their policy implications (Section 4).

The research of this paper uses a computational model, WITCH (Bosetti et al. 2006), designed to analyse the interactions between socio-economic systems, climate change and mitigation policies. ${ }^{4}$ WITCH is a regional integrated assessment hardlink hybrid model. Its top-down component consists of an intertemporal optimal growth model in which the energy input of the aggregate production function has been expanded to integrate a bottom-up-like description of the energy sector. World countries are grouped in twelve regions, whose strategic interactions are modelled through a dynamic game. A climate module and a damage function provide the feedback on the economy of carbon dioxide emissions into the atmosphere.

The WITCH model is structured so as to provide information on the optimal responses of world economies to climate damages and to model the channels of transmission of climate policy to the economic system. The dynamic and strategic features of the model, the energy sector specification and the technical change options make WITCH an especially suited tool to analyse the climate change policy issue, marked by medium-term investment choices and long-term economic dynamics and environmental responses. In WITCH, technological progress in the energy sector is endogenous, thus enabling us to account for the interplay between different timing and stringency of climate policies and induced technical change. For a more detailed description of the model and of the role of endogenous technical change the reader is referred to a recent OECD working paper (OECD 2008).

\section{The cost of delaying action}

As discussed in the Introduction, uncertainty surrounding the willingness and ability to take global action - and the expectation that such uncertainty may be resolved in the next one or two decades-may induce policymakers to adopt a waiting strategy.

\footnotetext{
${ }^{4}$ See www.feem-web.it/WITCH for more material regarding the model description and output.
} 
What then, are the economic implications of continuing along a business-as-usual path e.g. for the next 20 years, and agreeing on some stabilisation target at a later date?

In this section, we explore the global implications of different decisions about the course of action to be followed in the coming 20 years on the Net Present Value (NPV) of policy costs for this century. In particular, we assess the sensitivity of $450 / 550$ ppmv $\mathrm{CO}_{2}$ only (roughly 550/650 all greenhouse gases) policy costs to a 20year delay in action, and also the cost of initiating a climate mitigation policy (either stringent or mild) and subsequently dropping it.

The analysis is performed by assuming that a global cap and trade scheme is implemented (either now or with a 20 years delay) to achieve a given stabilisation target (either 450 or 550 ppm $\mathrm{CO}_{2}$ only). ${ }^{5}$ The optimal investment and innovation strategies (particularly in the energy sector) are then computed and the climate policy economic cost is determined (see Bosetti et al. 2007 for a description of how policy costs are computed with WITCH). Table 1 summarises our main results.

If world policymakers jointly start taking action now to control climate change, the net present value of stabilisation costs at a 3\% (5\%) discount rate ranges from $0.2 \%$ $(0.3 \%)$ to $3.5 \%(2.3 \%)$ of Gross World Product (GWP), depending on whether we undertake a mild policy or a stringent policy. These figures represent the additional cost of stabilisation, compared to a world in which no costly abatement actions are undertaken (the BAU scenario). Notice that our figures are somewhat higher than the IPCC's estimates, since we explicitly account for free-riding incentives and other inefficiencies deriving from environmental, R\&D and market externalities (see Bosetti et al. 2007). ${ }^{6}$

As shown in Table 1, the cost implications of delaying actions for 20 years vary considerably. In particular, they crucially depend on whether policymakers decide on a mild or stringent policy after the delay period. While the costs of delaying to undertake mild actions are relatively modest (the net present value of the cost is equivalent to $0.4 \%$ of GWP as opposed to $0.2 \%$ of GWP with an immediate start), moving from the business-as-usual to a stringent climate stabilisation target after the 20 -year delay is extremely costly - up to $7.6 \%$ (5.5\% at $5 \%$ discounting) of the net present value of GWP over this century. This represents either an increase of policy costs of about $130-140 \%$, or an equivalent loss of 5.7 (2.2 at $5 \%$ discounting) trillion USD per year of delay. Of course, this is likely to disrupt the common understanding of the economic feasibility of any stringent action as currently perceived by policymakers.

Another important result emerges from our analysis: a policy strategy that immediately begins to undertake some emissions reductions that are consistent with a 550 ppmv $\mathrm{CO}_{2}$ only stabilisation target and in 20 years reverts to the businessas-usual scenario, does not harm global welfare. It actually leads to a very mild increase of GWP, thanks to the internalisation of the various externalities on carbon, exhaustible resources, and innovation. The same mild mitigation policy can be

\footnotetext{
${ }^{5} \mathrm{We}$ assume all countries to take action at the same time. An analysis of the implications of differentiated timing of action is provided in Bosetti et al. (2008).

${ }^{6}$ Most existing studies assume a central global planner and therefore internalise all these inefficiencies and externalities. In our study, we compute the optimal non-cooperative Nash equilibrium policies instead.
} 
Table 1 The cost implications of delayed action, NPV GWP loss to 2100, discounted at 3\% (and 5\%)

\begin{tabular}{clll}
\hline & $\begin{array}{l}\text { Continue along the } \\
\text { business as usual path }\end{array}$ & $\begin{array}{l}\text { Undertake a mild } \\
\text { climate control policy }\end{array}$ & $\begin{array}{l}\text { Undertake a stringent }^{\mathrm{b}} \\
\text { climate control policy }^{\circ}\end{array}$ \\
\hline $\begin{array}{c}\text { Take action now } \\
\text { Wait 20 years on the }\end{array}$ & - & $0.3 \%(0.2 \%)$ & $3.5 \%(2.3 \%)$ \\
$\begin{array}{c}\text { business as usual path } \\
\begin{array}{c}\text { Wait 20 years on a mild } \\
\text { policy }\end{array}\end{array}$ & $-0.03 \%(0.06 \%)$ & $0.4 \%(0.3 \%)$ & $7.6 \%(5.5 \%)$ \\
\hline
\end{tabular}

a 550 ppmv $\mathrm{CO}_{2}$ only, roughly equivalent to $650 \mathrm{ppmv}$ all gases

b450 ppmv $\mathrm{CO}_{2}$ only, roughly equivalent to 550 ppmv all gases

tightened at a cost lower than when continuing along a business-as-usual path for the next 20 years: the net present value of the costs of shifting from a mild to a stringent policy reaches $4.2 \%(2.7 \%)$ of GWP, still well below the cost of inaction for 20 years followed by embracing a stringent climate policy in 20 year's time.

The policy implications of this exercise are quite clear, and support the arguments that call for immediate action to tackle climate change (see, e.g. Stern 2007, 2008): if we continue doing nothing for 20 years, the costs of shifting from a business-as-usual to a stringent climate policy are extremely high. On the other hand, undertaking some form of mild stabilisation policy seems to be a hedging strategy which, at virtually no cost, would allow us to revert to business-as-usual and, at relatively modest cost, to undertake more decisive action if a more stringent stabilisation policy is decided upon.

The cost effectiveness of starting with a mild policy, leaving open the possibility of more stringent actions in the future has also been highlighted in previous research (see e.g. Olmstead and Stavins 2006; Olmstead 2007), even though no quantitative assessment was provided. Yet, the political feasibility of such an approach-from an intergenerational perspective-can be questioned (Frankel 2007; Aldy et al. 2001). In particular, such a strategy would impose a constraint on the action of future decision makers and political leaders, who would be forced on a climate control path determined by current policy makers. Current decision makers should therefore seek to reduce the risk that future policy makers may reject the policy actions determined by their decisions, thus taking into account the uncertainty over the willingness to control climate change in the future whilst taking action today.

In the next section, we formalise the uncertainty that surrounds the climate objective. This enables us to devise the optimal abatement strategy and portfolio of mitigation technologies taking into account that future policymakers may choose from a range of different climate targets.

\section{Optimal stabilisation strategy under climate target uncertainty}

In this section, we use a stochastic programming version of the WITCH model to investigate an optimal policy strategy given the uncertainty about the stringency of the stabilisation target that will eventually be established in an international climate agreement. This version of WITCH has been used to analyse other forms of uncertainty in climate change economics (see for example Bosetti and Tavoni 
2009 , for an analysis of the uncertain effects of R\&D). We frame the analysis on a scenario tree, solve for all scenarios simultaneously and account for non anticipativity constraints (action has to be the same for different scenarios before the disclosure of uncertainty, while the optimal reaction to the information revealed when uncertainty is eliminated is allowed afterwards).

This formulation enables us to devise the optimal strategy before uncertainty is disclosed, and identify potentially optimal hedging behaviour. It also enables us to determine the most suitable portfolio of mitigation technologies given the uncertainty on stabilisation targets that will be adopted in the future. ${ }^{7}$ Let us assume that uncertainty about the climate target is resolved 27 years from now, in $2035 .{ }^{8}$ However, today, the future target is unknown and three scenarios are assumed to emerge with equal probability:

- $B A U($ no target): no constraint on emissions. No agreement on a common target is achieved, and countries are free to adopt their own BAU emission levels. This is an extreme scenario in which there is a complete stall in international negotiations and consequently single regions decide not to commit to any mitigation from 2035 on. It could also be read as a scenario in which by 2035 either we discover that climate change theories are unfounded (or un-anthropogenic) or we discover a perfect geo-engineering solution that allows carbon emissions to be decoupled from climate warming.

- 550 ppm $\mathrm{CO}_{2}$ stabilization. We assume an international climate agreement is reached, with a target of carbon concentrations in 2100 of $550 \mathrm{CO}_{2}$ only (650 all GHGs).

- 450 ppm $\mathrm{CO}_{2}$ stabilization. We assume an international climate agreement is reached, with a target of carbon concentrations in 2100 of $450 \mathrm{CO}_{2}$ only (550 all GHGs).

We assume each possible target is equally likely ${ }^{9}$ to express an uninformative a priori that foresees equal chances of any of the three scenarios materialising.

\subsection{Emissions and investments in the energy sector}

Using the above assumptions, we compute the optimal investment path for all energy technologies, for physical capital and for R\&D as a non-cooperative equilibrium of the game among the twelve world regions represented in WITCH. Figure 1 reports

\footnotetext{
${ }^{7}$ Such a risk-management approach is particularly important given the low capital turnover of energy investments. As a consequence investment decisions crucially depend on potential future climate policy scenarios. Inertia in the energy sector could support an argument in favour of early deployment of mitigation technologies, given that once an investment is made, it can last for decades, let alone early retirement or "retrofitting" cleaner technologies, both notoriously expensive (Stern 2007). On the other hand, a similar argument could hold for capital irreversibility of investments in renewables, thus suggesting that "wait and see" would be the optimal choice (Kolstad 1993, 1996a, b).

${ }^{8}$ The specific choice of the date has been made taking into account that a longer procrastination might be incompatible with the eventual attainment of a serious stabilization objective, and that an earlier one would leave us with a too short time frame to be analysed. Nonetheless, the direction of results is expected to remain valid, as shown in Bosetti and Tavoni (2009).

${ }^{9} \mathrm{We}$ also experimented with different probability distributions, and found general results to hold.
} 

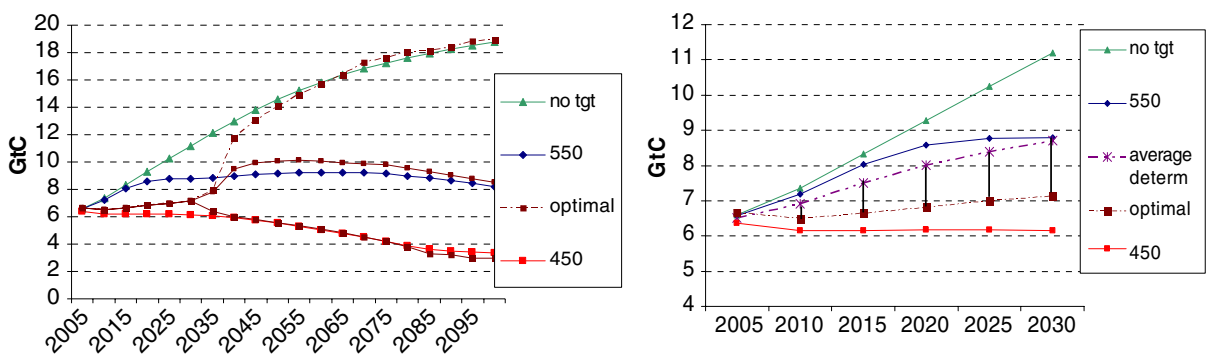

Fig. 1 Fossil fuel emissions for optimal stochastic and deterministic cases, to 2100 (left) and to 2030 (right)

the resulting global carbon emissions trajectories over this century for the stochastic case and the deterministic cases of no target, 550 and 450, up until 2100 (left panel) and in more detail to 2030 (right panel).

The figure shows the three different deterministic cases vis à vis the stochastic one that takes into account the fact that all three are possible. It provides clear evidence of hedging behaviour: the optimal strategy before uncertainty is resolved is to engage in significant mitigation. In 2030, emissions are $57 \%$ lower than in the BAU scenario, essentially the same as they are today. That is to say, in a world that has an equal chance of being confronted with no climate policy, a mild policy or a stringent policy in 30 year's time, the best strategy in the short-term (for the next two decades) is to minimise emission growth. Emissions in 2030 would also be $23 \%$ lower than the target prescribed by the mild policy, and only $14 \%$ higher than the more stringent one.

The low level of emissions in the stochastic scenario is driven by the possibility of a stringent climate target, albeit this has just a $33 \%$ chance of occurring. The convexity of marginal abatement costs in the mitigation levels is the reason for this risk-averse approach. As shown in the right panel of Fig. 1, the optimal emission path is always below the average of the three deterministic cases, by $1.6 \mathrm{GtC}$ in 2030 , or $22 \%$. This quantifies the dimension of the precautionary strategy.

From a public policy perspective, it is interesting to see how the portfolio of mitigation options is affected by explicit accounting for climate target uncertainty. Figure 2 highlights two important implications for investment strategies, aimed at improving energy and carbon efficiency respectively. Optimal public expenditure on R\&D to enhance energy efficiency in the stochastic case (left panel) is close to
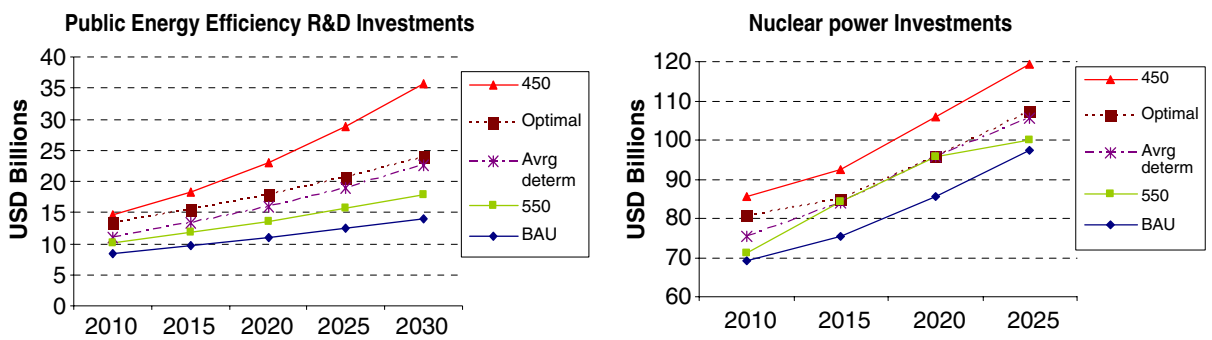

Fig. 2 Investments in Energy Efficiency R\&D (left) and Nuclear power capacity (right) 
the amount spent in the more stringent scenario especially in the first period, and always above the average of the deterministic cases. This indicates that energy-saving measures are optimal in the short term even when a weak stabilisation target is likely to be set in the future. This is in line with the common belief that energy efficiency measures are a priority and should be undertaken anyway.

Nonetheless, in order to attain the emission reductions required by the optimal hedging strategy, the energy sector should also adopt substantial decarbonisation measures; the right panel of Fig. 2 shows that in the stochastic case investments in carbon-free nuclear power plants are above those in the BAU scenario and in the $550\left(\mathrm{CO}_{2}\right.$ only) scenario. Again, these optimal investment profiles describe a hedging strategy that would decrease the carbon intensity of energy beyond the average of the three deterministic cases.

In terms of the policy prescriptions that we can derive from the optimal trajectory, investments in public energy R\&D should be roughly doubled with respect to those in the BAU scenario, which would be a spending policy akin to the innovation effort of the 1980s. A similar path should be undertaken for increasing nuclear power capacity, with average global additions at about $15 \mathrm{GW}$ per year up to 2035 .

Figure 3 shows the aggregated picture of departures from the BAU scenario in terms of energy intensity (total primary energy supply over GWP) and carbon intensity of energy (carbon emissions over total primary energy supply). The picture shows that optimal climate policy under uncertainty requires action for both energy efficiency and decarbonisation, and that more ambitious targets require a shift along both the horizontal and vertical axes.

Once again, we see how the optimal strategy under uncertainty lies between the 450 and 550 scenarios. It also lies to the right of the average of deterministic cases, reinforcing the message that the hedged mitigation portfolio should give comparable priority to energy savings and carbon-free technology development.

\subsection{The economic cost of sub-optimal strategies}

Another interesting exercise is to quantify the economic loss resulting from noncompliance with the hedging strategy detailed in the previous section, and the pursuit of the optimal investment strategies for the deterministic cases. In order to do this, we run the stochastic version of the model, but fix all the choice variables to those

Fig. 3 Improvements of energy and carbon intensities over BAU, 2010-2030

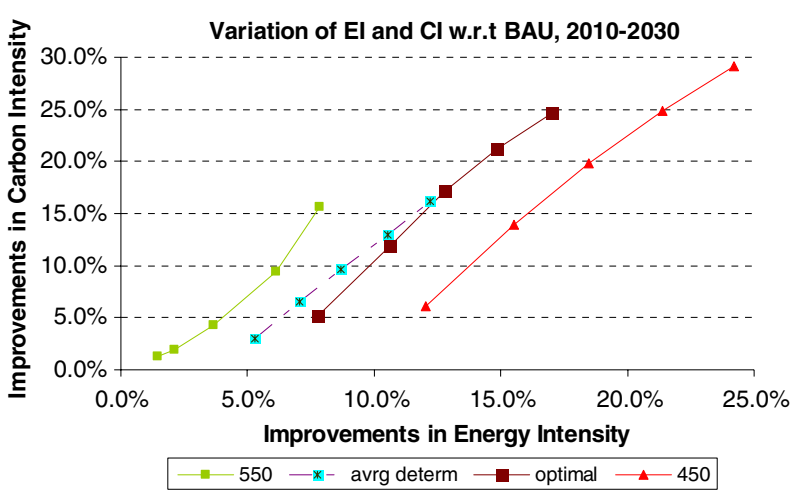


Fig. 4 GWP differences of sub-optimal strategies w.r.t the optimal hedging one

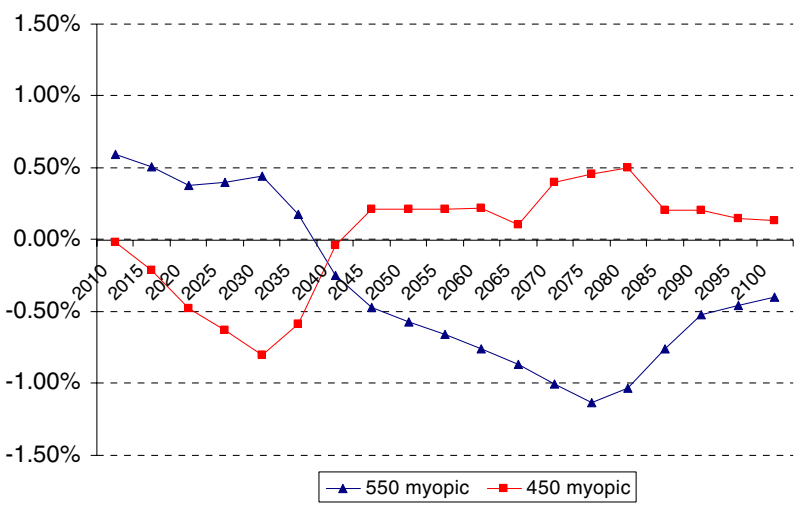

of the three deterministic cases until 2035 (the time frame to uncertainty resolution); from that point on, the model is free to optimise for each of the three states of the world, given the sub-optimal choices undertaken during the preceding periods. This enables us to quantify the economic losses that would result from sticking to either a BAU Scenario, a $550 \mathrm{ppm}$ stabilisation policy or a $450 \mathrm{ppm}$ stabilisation scenario (thus not adhering to the optimal strategy) in the periods before the final outcome of the international agreement on climate is known.

The first important result is that following the BAU scenario from now to 2035 does not allow a feasible solution to the optimisation problem if the target after 2035 is the ambitious one (450 $\left.\mathrm{CO}_{2}(550 \mathrm{e})\right)$. In other words, a BAU strategy for the next three decades precludes the attainment of the more stringent stabilisation target. This result extends the one seen in the first part of the paper, which showed that policy costs increase sharply with the period of inaction. It should be noted that accounting for technologies that can achieve negative carbon emissions might allow a solution even in this case; however, such a scenario is highly questionable and has thus not been included in this analysis. ${ }^{10}$

Sub-optimal strategies aiming at 550 and 450 result in more and less emissions (respectively) than the optimal strategy does before 2035-and vice versa thereafter-as noted in the previous section. We thus expect that following a mild 550 policy would lead to improved outputs in the first decades, followed by deterioration, and that the opposite would be true if we followed an emission mitigation policy that was more stringent than the optimal one, such as aiming for the 450 target. This is what is shown in Fig. 4, where the gap between the expected value of Global World Product for the sub-optimal cases and the optimal one is shown.

One can see that committing to more mitigation results initially in economic loss, but leads to a higher output after the resolution of uncertainty, due to the fact that the burden of meeting the stringent target in the future has been alleviated. On the other hand, a sub-optimal 450 strategy inflicts costs that are somewhat higher than the benefits of a milder choice $(-0.8 \%$ GWP losses in 2035 for 450 , as opposed to

\footnotetext{
${ }^{10}$ In addition, the model is -if any- prone to underestimate the stickiness of the investment strategies and the effects of the long lived capital of some energy related stocks, such as the efficiency of buildings or of the transport infrastructure.
} 
Table 2 Economic penalty (extra NPV GWP loss) of sub-optimal strategies at 450 and 550 (w.r.t to the optimal one under uncertainty)

\begin{tabular}{lcc}
\hline Discount rate for & $3 \%$ & $5 \%$ \\
NPV calculation & & \\
\hline Sub-optimal 550 & $17.2 \%$ & $0.01 \%$ \\
Sub-optimal 450 & $1.7 \%$ & $16.2 \%$ \\
\hline
\end{tabular}

$+0.45 \%$ gains for 550 ) in the short term. The picture reverses after 2035, when the costs of under-abatement before shifting to a stringent policy are higher than the benefit of a more virtuous early strategy.

Eventually, the way we discount variations of GWP over time determines the merit order of either sub-optimal strategies, as Table 2 shows. Using a low discount rate (3\%), we find that the sub-optimal $550 \mathrm{ppm}$ strategy entails an economic penalty of around $17 \%$ (from the 1.4\% GWP loss for the stochastic case to 1.7\% GWP loss in the myopic one), whereas in the $450 \mathrm{ppm}$ case, the loss is much smaller $(1.7 \%$, from $1.4 \%$ to $1.5 \%$ ). The opposite holds when we discount at a higher rate (5\%), which essentially implies more emphasis on the costs and benefits attained in the first half of the century: here, a milder climate change strategy has almost no negative economic impact on policy costs, as it allows for greater initial economic growth, whereas a more ambitious one leads to a penalty of about $16 \%$.

Summing up, the optimal strategy before 2035 in the presence of uncertainty about future stabilisation targets is a mitigation policy that results in an emissions trajectory that lies between the 450 and 550 trajectories. Choosing either of those two policies results in economic inefficiency ranging from about zero to $16-17 \%$ of GWP, depending on the discount rate. Pursuing less mitigation than the $550 \mathrm{ppm}$ policy significantly increases these extra costs, leading to the impossibility of meeting the climate objective in the case of zero early mitigation action.

\section{Conclusions}

Despite the emergence of a scientific consensus over the necessity of stringent climate targets, no effective international agreement to reduce carbon emissions has yet been achieved. As a consequence, the definition of a global stabilisation objective for the next decades is at present, and for the foreseeable future, very uncertain. The economic analysis of climate change policies should take this uncertainty into account to avoid misleading policy recommendations.

This paper constitutes an attempt to provide better information to policymakers by identifying the short-term implications of uncertainty about future climate targets and by computing the cost of delaying the introduction of effective mitigation strategies.

Despite general warnings on the risks of inaction, most estimates of the cost of mitigation policies have tended not to consider such costs in the calculation. In the first part of the paper, we show that this cost is far from negligible, even in a model in which technology is flexible and endogenous, and R\&D investments are optimally chosen. We quantify the cost of a 20-year delay in action as an increase of GWP losses of about $140 \%$, or in the range (depending on discounting) of 2.2-5.7 trillion 
USD per year of delay. We also show how committing to a mild abatement effort in the short term might substantially reduce the cost of delaying action.

In the second part, we analyse how short-term mitigation strategies could hedge against the uncertainty of future climate targets. Results point clearly to a precautionary behaviour in which emissions are considerably reduced even before an agreement is signed. We also show that the optimal short-term portfolio of technologies includes investments in energy efficiency improvements, but also in technologies that enhance decarbonisation.

Finally, we quantify the economic inefficiencies for different extreme short-term strategies (ranging from inaction to strong emission reduction) that do not account for the uncertainty of future climate policies. We show that the adoption of a "wrong" policy strategy in the short term may considerably increase the economic costs of GHG stabilisation.

The results presented in this paper support the adoption of a precautionary approach to climate policymaking. The optimal mitigation strategy in the presence of uncertainty is a highly ambitious one (e.g. the one that achieves a $450 \mathrm{ppm}$ target) rather than a moderate one. At the same time, the cost of adopting a moderate climate strategy in the first decades, and then shifting to the ambitious one if necessary, is relatively small. This result is consistent with the conclusion that delaying action is not too costly if a moderate climate policy is adopted in the short term-but it may become very costly if no action is taken at all.

The model used in this paper is limited in relation to the exogenous probability distribution of future climate targets. Further research will focus on endogenising the uncertainty over the probabilities of more or less stringent future climate policies. These probabilities are indeed a function of the mitigation efforts undertaken over time, and of the resulting technological progress that would be induced.

\section{References}

Aldy JE, Orszag PR, Stiglitz JE (2001) Climate change: an agenda for global collective action timing of climate change policies. Pew Center on Global Climate Change, Washington DC

Aldy JE, Stavins RN (2007) Architectures for agreement. Addressing global climate change in the post-Kyoto world. Vol. Cambridge University Press, New York

Bahn O, Haurie A, Malham R (2008) A stochastic control model for optimal timing of climate policies. Automatica 44:1545-1558

Bosetti V, Carraro C, Galeotti M, Massetti E, Tavoni M (2006) WITCH: a world induced technical change hybrid model. The energy journal, special issue on hybrid modeling of energyenvironment policies: reconciling bottom-up and top-down: 13-38

Bosetti V, Carraro C, Massetti E, Tavoni M (2007) Optimal energy investment and R\&D strategies to stabilise greenhouse gas atmospheric concentrations. FEEM Working Paper, Milan

Bosetti V, Carraro C, Tavoni M (2008) Delayed participation of developing countries to climate agreements: should action in the EU and US be postponed? FEEM Working Paper, Milan

Bosetti V, Tavoni, M (2009) Uncertain R\&D, backstop technology and GHGs stabilization. Energy Econ 31:S18-S26

EC Communication (2007) Limiting global climate change to 2 degrees celsius: the way ahead for 2020 and beyond

Fisher A (2002) Irreversibility and catastrophic risk in climate change. In: van Ierland E, Weikard $\mathrm{H}$, Wesseler J (eds) Risk and uncertainty in environmental and resource economics. Wagenigen University, Wagenigen

Frankel J (2007) Formulas for quantitative emission targets. In: Aldy JE, Stavins RN (eds) Architectures for agreement. Addressing global climate change in the post-Kyoto world. Cambridge University Press, New York 
Ha-Duong M, Grubb MJ, Hourcade J-C (1997) Influence of socioeconomic inertia and uncertainty on optimal $\mathrm{CO}_{2}$ emission abatement. Nature 30:270-273

IEA (2002) Beyond Kyoto: energy dynamics and climate stabilisation. Vol. International Energy Agency, Paris

Ingham A, Ma J, Ulph A (2007) Climate change, mitigation and adaptation with uncertainty and learning. Energy Policy 35:5354-5369

IPCC (2007) Climate change 2007: synthesis report. Contribution of working groups I, II and III to the fourth assessment

Karp L, Zhang J (2006) Regulation with anticipated learning about environmental damages. J Environ Econ Manage 51:259-280

Kolstad C (1993) Looking vs. leaping: the timing of $\mathrm{CO}_{2}$ control in the face of uncertainty and learning. In: Kaya Y, Nakicenovic N, Nordhaus WD, Toth FL (eds) Costs, impacts and benefits of $\mathrm{CO}_{2}$ mitigation. IIASA, Vienna

Kolstad C (1996a) Fundamental irreversibilities in stock externalities. J Public Econ 60:221-233

Kolstad C (1996b) Learning and stock effects in environmental regulations: the case of greenhouse gas emissions. J Environ Econ Manage 31:1-18

Kosobud RDT, South D, Quinn K (1994) Tradable cumulative $\mathrm{CO}_{2}$ permits and global warming control. Energy J 15:213-232

Manne A, Richels R (1995) The greenhouse debate. Economic efficiency, burden sharing and hedging strategies, EPRI

Newell R, Hall D (2007) U.S. climate mitigation in the context of global stabilization. Resources for the Future, Washington DC

Nordhaus W, Popp D (1997) What is the value of scientific knowledge? An application to global warming using the PRICE model. Energy J 18:1-47

OECD. Burniaux JM, Chateau J, Duval R, Jamet S (2008) The economics of climate change mitigation: policies and options for the future. OECD working paper, December 2008

Olmstead SM (2007) The whole and the sum of its parts. In: Aldy JE, Stavins RN (eds) Architectures for agreement. Addressing global climate change in the post-Kyoto world. Cambridge University Press, New York

Olmstead SM, Stavins RN (2006) An international policy architecture for the post-Kyoto era. Am Econ Rev 96:35-38. Papers and Proceedings

Richels R, Edmonds J (1997) On stabilizing $\mathrm{CO}_{2}$ concentrations-cost-effective emission reduction strategies. Environ Model Assess 2:251-265

Schneider SH, Goulder LH (1997) Achieving low-cost emissions targets. Nature 389:13-14

Stern N (2007) The economics of climate change: the stern review. Vol. Cambridge University Press, Cambridge

Stern N (2008) Key elements of a global deal on climate change. The London School of Economics and Political Science, London

Ulph A, Ulph D (1997) Global warming, irreversibility and learning. Econ J 107:636-650

Wigley TML, Richels R, Edmonds J (1996) Economic and environmental choices in the stabilization of atmospheric $\mathrm{CO}_{2}$ concentrations. Nature 379:240-243

Yohe G, Andronova N, Schlesinger M (2004) To hedge or not against an uncertain climate future. Science 306:416-417 